\title{
Different Relations of Religion and Mental Health
}

\section{Comparing Middle Eastern Muslim Refugee and Immigrant Adolescents}

\author{
Usama EL-Awad ${ }^{1,2}$, Atefeh Fathi ${ }^{3}$, Arnold Lohaus ${ }^{2}$, Franz Petermann ${ }^{1, \dagger}$, \\ and Tilman Reinelt ${ }^{1,4}$ \\ ${ }^{1}$ Center for Clinical Psychology and Rehabilitation, University of Bremen, Germany \\ ${ }^{2}$ Faculty of Psychology and Sports Sciences, Bielefeld University, Germany \\ ${ }^{3}$ Center for Psychosomatic Psychotherapeutic Rehabilitation, Luisenklinik, Stuttgart, Germany \\ ${ }^{4}$ Clinic for Neonatology, University of Zurich and University Hospital Zurich, Germany
}

\begin{abstract}
Background: Religiosity can foster mental health after traumatic experiences. Yet, religiosity among Muslim immigrants has also been linked to separation-oriented acculturation, which is linked to reduced mental health. Therefore, the function of religiosity for resilience in Middle Eastern refugee and immigrant adolescents might differ as their migration contexts differ in terms of traumatic experiences and the nature of cultural interactions. Aims: This study examined whether religiosity is associated with better mental health after traumatic experiences, particularly among young refugees. In addition, it was explored whether religiosity is associated with better mental health among refugees through less marginalization and whether religious immigrant peers show worse mental health through stronger separation. Method: 135 adolescents $\left(M_{\text {Age }}=18.25\right.$ years, $\left.S D=1.73 ; n_{\text {refugees }}=75, n_{\text {immigrants }}=60\right)$ completed self-reports on religiosity, mental health, trauma, and acculturation orientations. Regression analyses were calculated examining group-specific differences in potential moderating effects of religiosity on the relationship between trauma exposures and internalizing symptoms. Furthermore, potential indirect effects of religiosity on internalizing symptoms via acculturation orientations were investigated. Results: Stronger religiosity was associated with better mental health following trauma exposure. No group-specific differences were observed. While religious refugee adolescents reported less marginalization associated with fewer internalizing symptoms, religious immigrant peers reported more separation and internalizing symptoms. Limitations: Results are limited to male Muslim adolescents in Germany. The cross-sectional nature prohibits any implications for causal dynamics in the associations. Conclusion: Religiosity is generally protective against post-traumatic consequences, but associations with acculturation differ across migration contexts.
\end{abstract}

Keywords: refugee adolescents, migrant adolescents, religion, mental health, acculturation

Due to global wars and turmoil, Germany has received almost 1.5 million refugees by 2020, most coming from Muslim-majority countries in the Middle East, such as Syria, Afghanistan, Iraq, or Iran (Federal Office for Migration and Refugees, 2020). Half of the asylum seekers are young men between the ages of 16 and 24 years (Federal Office for Migration and Refugees, 2017). They are part of a society where almost a third of the young population comprises immigrants or their direct descendants, many of them with roots in the Middle East.

Many refugee adolescents (RA) have experienced potentially traumatic events, such as war or the loss of family and friends. While most of these events occur before or during the flight, about $25 \%$ of RA report at least one potentially traumatic event (e.g., being beaten) in the host country
(EL-Awad et al., 2021). In addition, RA experience acculturative stress when they adapt to a new language or different cultural values and norms. In particular, experiences of racial or religious discrimination are associated with an increased risk of worsened mental health among Muslim RA in Western countries, as discrimination and racism against Muslims have increased significantly since the terrorist attacks of September 11, 2001 (Müller, 2017). Indeed, even second-generation immigrants from Middle Eastern countries frequently report experiences of discrimination, resulting in more stress as compared to native-born youth (Giuliani et al., 2018). Accordingly, acculturation-specific difficulties related to RA account for a similar or even greater proportion of the variance in internalizing symptoms than the experience of traumatic events (Lincoln et al., 2016). 
However, most adolescents with an immigrant-origin (IA; first- and second-generation immigrants) settle well and have stable mental health (Berry, 1997). In addition, prevalence rates for mental disorders in RA vary considerably. For example, the prevalence of post-traumatic stress disorder varies from $11 \%$ to $73 \%$ and depression from $6 \%$ to 53\% (Fazel et al., 2012; Hodes et al., 2008). Hence, the majority of IA and a significant portion of RA can be considered to be resilient.

\section{Resilience in Refugee and Immigrant Adolescents}

Resilience, which means staying healthy despite adverse circumstances, can be achieved in various psychological ways. In general, genetic-biological pathways can be distinguished from pathways that lead through the acquisition and use of compensatory skills or cognitive restructuring and the acceptance of negative experiences as part of personal growth (Reinelt et al., 2016). However, the processes that lead to resilience may be different for different groups and contexts. Particularly about compensatory processes, it may be possible that factors that buffer post-traumatic stress do not protect against (or even exacerbate) everyday acculturative stress, and vice versa. According to a recent integrative risk and resilience model for immigrant youth (Suárez-Orozco et al., 2018), resilience is influenced at multiple levels in IA and RA. On a personal level, cultural competencies could reduce acculturative stress, while family or community support could promote overall health.

However, IA and RA differ in their preconditions. While almost all RA have experienced potentially traumatic events due to war, IA's traumatic experiences are mostly related to family conflicts (EL-Awad et al., 2021). In contrast, many RA arrived in the host country unaccompanied and thus have no support from their family (Federal Office for Migration and Refugees, 2017). On the other hand, IA were born and raised in Germany, grew up in schools with native peers, and had more support from the majority society than RA (Schwartz et al., 2010). In addition, RA have to learn a new language in adolescence, whereas IA have already learned the language at pre-school age or at school. However, growing up in the host country is likely to bring a different perspective on discrimination, as perceptions of discrimination may increase with the length of stay (Suárez-Orozco et al., 2018).

Therefore, RA and IA provide the context to examine the differential impact of potential protective factors. One factor that has been shown to influence coping with traumatic experiences and acculturative stress is religiosity (Adedoyin et al., 2016; Finch \& Vega, 2003). Islam shapes the national identity in almost all Middle Eastern countries and is firmly intertwined with the culture of origin, influencing common values, food (e.g., halal), and traditions (Gregg, 2005; Kumaraswamy, 2006). Thus, religiosity could be a protective factor in investigating the different associations in developing resilience among Muslim RA and IA from the Middle East in Germany.

\section{Religiosity and Trauma}

Religion refers to a systematic set of cultural elements, including rites, traditions, and beliefs in the Almighty (Cohen, 2009). An orientation toward a religious motive (intrinsic religiosity) manifests itself in subordinating needs of all kinds by aligning them with one's religious beliefs and traditions (Allport \& Ross, 1967). Practitioners integrate religion into their daily lives, leading to greater religious activity - both in public through attendance at religious services and in private through prayer or the use of religious media (Koenig \& Büssing, 2010). Religious dimensions, therefore, include cognitive and behavioral components and provide resources for coping strategies, especially when facing severe stress (Smith et al., 2004). For example, religiosity has been associated with changes in the reappraisal of potentially traumatic experiences and the use of coping strategies (Pargament et al., 1990). Religious assessments can attribute the cause of events to the will of God (Shortz \& Worthington, 1994). Therefore, religiosity could help RA cope with traumatic experiences by giving meaning to what has happened and preventing a ruminative search for reasons. Additionally, religious activities might foster resilience by providing social support from local communities or families (Pargament, 2011).

However, research has demonstrated a main effect of religiosity on internalizing symptoms regardless of the extent of traumatic experiences and a moderating effect on the relationship between traumatic experiences and internalizing symptoms (Smith et al., 2004). While the first suggests that religiosity generally supports adolescents' mental health after traumatic exposure, the latter postulates that adolescents who have experienced a high level of traumatic events might benefit the most from religion.

\section{Religiosity and Acculturation}

Acculturation means cultural learning and change in behavior and cognition when encountering another culture (Berry, 1997). Adolescents may align themselves with the new culture (assimilation) or with the original culture (separation), the balance between cultures (integration), or reject them altogether (marginalization). In terms of mental 
health, integration is related to reductions in depression and anxiety (Lincoln et al., 2016). Marginalization, on the other hand, is associated with poorer mental health than other styles. Particularly for non-Western RA in Western countries, marginalization results in social isolation and exclusion (Lincoln et al., 2016). Moreover, post-traumatic stress can lead to mistrust and social problems, making it difficult to establish cultural participation (Majumder et al., 2015). By following Islam, adolescents can avoid an unstable environment by building cultural identity and receiving social support from the religious community (Güngör et al., 2013). In this way, religiosity could protect RA from marginalization and promote a resilient development (Ní Raghallaigh, 2011).

Muslim IA born in the host country or immigrated at a young age ( 1.5 generations) are in a longer interaction with the majority society compared to RA. They are acculturated in their primary culture, and the societal expectation of assimilating weighs more heavily on them, leading to cultural conflicts (Kunst \& Sam, 2014). Moreover, implicit negative attitudes and hostilities in parts of society toward Muslims create social barriers for Muslim youth to engage with religious traditions or beliefs while integrating into the majority society (Statham \& Tillie, 2016). For example, Muslim youth experience higher acculturative stress because they have difficulties balancing their religious activities with school and work (Roth, 2020). Racial and religious discrimination, as well as social exclusion, may force Muslim youth to become separated from their nonreligious peers by focusing on peers of the same ethnic group who support their religiosity (Güngör et al., 2013; Statham \& Tillie, 2016). Particularly in a less pluralistic Western society, separation-oriented Middle Eastern youth suffer from more severe internalizing symptoms (Brand et al., 2017). However, the relationship between religiosity and separation may be specific to first- and second-generation IA at a more advanced stage of acculturation, as they tend to experience discrimination more strongly (see Suárez-Orozco et al., 2018).

\section{The Present Study}

This study examined the role of religiosity in resilience in RA and IA from two perspectives: first, religiosity was hypothesized to buffer against trauma-related mental health impairments. Second, the association between religiosity and mental health was expected to differ between groups regarding their acculturation orientation. We expected religiosity to protect RA from marginalization. In contrast, we expected religiosity to be related to separation in IA. Due to insufficient previous research, no hypotheses were formulated for the relationships between religiosity and separation in RA or religiosity and marginalization in IA. Likewise, no assumptions were made about integration or assimilation, as the literature states that there is no relationship between religiosity and majority cultures among non-Western minorities (e.g., Güngör et al., 2013). However, potential associations were explored. The following hypotheses were stated:

Hypothesis 1 (H1): (a) A higher number of potentially traumatic events is associated with more suffering from internalizing symptoms. This effect is moderated by religiosity, with higher levels weakening the relationship between potentially traumatic events and internalizing symptoms. (b) The moderating effect of religiosity is larger in RA than in IA (see Figure 1).

Hypothesis 2 (H2): Higher levels of religiosity are associated with (a) lower levels of marginalization in RA and therefore with less internalizing symptoms; (b) higher levels of separation in IA and therefore with more internalizing symptoms.

\section{Method}

\section{Participants and Procedure}

Between 2016 and 2019, 135 RA and IA participated in this study, part of a larger German research project examining adolescent mental health risks and protective factors, particularly among accompanied and unaccompanied RA. Participants were recruited in public institutions, schools, immigrant and refugee associations in three German cities. Only male youth participated, as the refugee youth in Germany were mainly young men from the Middle East (Federal Office for Migration and Refugees, 2017). To allow for cultural comparisons, the sample included only individuals from Middle Eastern countries (e.g., Afghanistan, Jordan) who were not forced to emigrate. All participants were asked if they or their families had experienced war or fled their home countries. RA $(n=75)$ and IA $(n=60)$ did not differ significantly with respect to age, $t(133)=$ $-0.8, p=.425$. On average, RA have stayed for 3 years $\left(S D_{\text {stay }}=1.3\right.$ years $)$ in the host country, while more than one-third of IA were born in Germany. The strong German language proficiency of foreign-born IA indicates that migration occurred in early childhood (1.5-generation). One participant from each group was excluded from the study, as they did not answer questions about religiosity. This left 133 youth $\left(n_{\mathrm{RA}}=74, n_{\mathrm{IA}}=59\right)$. Table 1 shows the characteristics of the participants. 


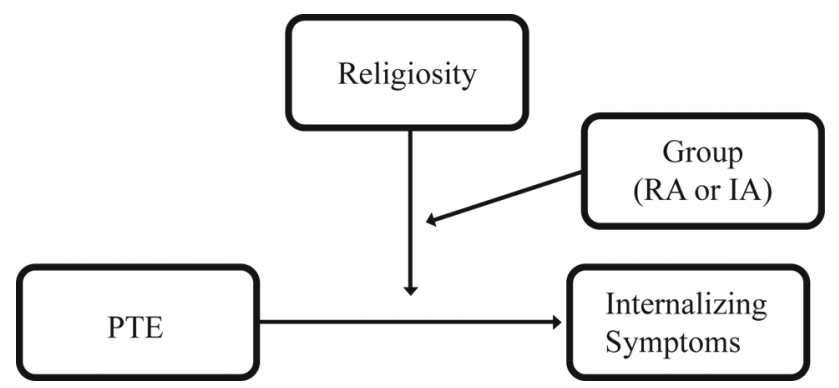

Figure 1. Conceptual diagram for group-specific examination of the religious moderation on the relationship of the number of potentially traumatic events and internalizing symptoms (Hypothesis 1). RA = refugee adolescents; $I A=$ first- and second-generation immigrant adolescents; PTE = potential traumatic events.

Data were collected in a German research center, in facilities of migrant associations, and in schools. Adolescents, parents, and legal representatives were informed in detail about participation and gave their written consent. Participants were informed before and during the study that data collection and storage would be anonymous. The non-political nature of the study and the exclusive scientific use of the data were emphasized to build trust. Before the study, the questionnaires were translated and back-translated into Arabic and Farsi following Brislin (1970). An interpreter was present during data collection to answer questions. The study lasted about two and a half hours, during which participants answered questionnaires on the computer and completed three behavioral tasks, while the measures used in this study lasted about 30 min. A local ethics committee approved the study.

\section{Measures}

\section{Religiosity}

The Duke University Religion Index (DUREL; Koenig \& Büssing, 2010) measures statements related to the intrinsic religiosity subscale ( 3 items; $\alpha=.91$ in the present study; e.g., experiencing the presence of God in life) that were rated on a 5 -point scale ( $1=$ definitely not true to $5=$ definitely true) and subsequently averaged. The level of religious activity was assessed by asking about the frequency of public religious activities such as religious meetings ( 1 item) and private religious activities such as prayers ( 1 item), each on a 6-point scale $\left(r_{\text {religiousactivity }}=.73, p<.001\right)$. The scale was designed to measure religious associations with mental health outcomes, making it particularly suitable for examining the research questions in the present study. An index of religiosity $(\alpha=.89)$ was built by combining the intrinsic religiosity subscale with both religious activity items (via $z$-scores).

\section{Acculturation Orientations}

The Essen Migration Inventory (EMI; Tagay et al., 2013) measures the expression of each acculturation orientation within the last 4 weeks (29 items): integration (8 Items, $\alpha=.65$ in the present study), assimilation (6 Items, $\alpha=.70$ in the present study), separation ( 9 Items, $\alpha=.69$ in the present study), and marginalization (6 Items, $\alpha=.68$ in the present study). Participants rated self-statements of cultural preferences, value dimensions, and identifications on a 4-point scale $(0=I$ strongly disagree to $3=I$ strongly agree $)$, while scores were calculated by averaging the item values. Because this scale captures orientations individually, there is no need to set artificial data split points, which allows for more accurate migration group-specific comparisons.

\section{Mental Health}

The Hopkins Symptom Checklist - 37A (HSCL-37A; Bean et al., 2007) has been developed to measure the mental health of refugee youth. It includes 25 items capturing internalizing symptoms ( $\alpha=.95$ in the present study) by combining depressive symptoms (15 items) and symptoms of anxiety (10 items). Items were rated on a 4-point scale $(0=$ never to $3=$ always $)$, and the outcome was calculated by the sum of the item scores.

\section{Potentially Traumatic Events (PTE)}

The Child and Adolescent Trauma Screening (CATS; Sachser et al., 2017) contains 38 items, including the PTE subscale (15 items), which asks participants whether they experienced events in 14 specified situations (response format: yes/no) (e.g., areas of family violence, war-related events, or community violence). An open-format question allowed participants to add to the list by asking about other stressful event types, then added to the total. This scale was developed for international use and showed good psychometric properties in cross-cultural studies.

\section{Statistical Analyses}

Data were analyzed in IBM SPSS Statistics 27. ExpectationMaximization (Dempster et al., 1977) was used to estimate missing values (around $4.5 \%$ of the scales), applied separately for each subscale and group. To test the association of religiosity and internalizing symptoms after PTE experiences (H1), a moderated regression analysis with percentile bootstrapped confidence intervals and $S E$ based on 10,000 resamples was conducted to allow for more precise distribution of estimators. PTEs served as the independent variable with religiosity as the moderator, including age and group as a covariate. Considering the sample size, group-specific differences between RA and IA regarding the interaction were explored using a 3D 
Table 1. Participant characteristics

\begin{tabular}{|c|c|c|c|}
\hline & \multicolumn{2}{|c|}{ Groups } & \multirow{3}{*}{$\begin{array}{c}\text { Total } \\
N=133\end{array}$} \\
\hline & RA & IA & \\
\hline & $n=74$ & $n=59$ & \\
\hline Age (in years), $M(S D)$ & $18.15(1.64)$ & $18.37(1.85)$ & $18.25(1.73)$ \\
\hline \multicolumn{4}{|l|}{ Country of origin, $n(\%)$} \\
\hline Syria & $46(62.2)$ & $2(3.4)$ & $48(36.1)$ \\
\hline Afghanistan & $18(24.3)$ & $10(16.9)$ & $28(21.1)$ \\
\hline Iran & $7(9.5)$ & $9(15.3)$ & $16(12.0)$ \\
\hline Iraq & $3(4.1)$ & $4(6.8)$ & $7(5.3)$ \\
\hline Germany & 0 & $21(35.6)$ & $21(15.8)$ \\
\hline Others (e.g., Jordan) & 0 & $13(22)$ & $13(9.8)$ \\
\hline Unaccompanied, n (\%) & $36(48.6)$ & 0 & $36(27.1)$ \\
\hline Education in host and origin country (school years), M (SD) & $9.00(2.53)$ & $10.92(1.49)$ & $9.83(2.33)$ \\
\hline Former employment, $n$ (\%) & $32(43.2)$ & 18 (30.5) & $50(37.6)$ \\
\hline \multicolumn{4}{|l|}{ Asylum status, $n(\%)$} \\
\hline Seeking (not yet registered) & $18(24.3)$ & 0 & $18(13.5)$ \\
\hline Applied & $12(16.2)$ & 0 & $12(9.0)$ \\
\hline Granted & $41(55.4)$ & 0 & $41(30.8)$ \\
\hline Rejected (tolerated stay) & $3(4.1)$ & 0 & $3(2.3)$ \\
\hline \multicolumn{4}{|l|}{ Religion, $n(\%)$} \\
\hline Islam & $62(83.8)$ & $38(64.4)$ & $100(75.2)$ \\
\hline Christianity & $7(9.5)$ & $5(8.5)$ & $12(9.0)$ \\
\hline Atheism/Agnosticism & $5(6.8)$ & $16(27.1)$ & $21(15.8)$ \\
\hline Others & 0 & 0 & 0 \\
\hline
\end{tabular}

Note. $\mathrm{RA}=$ refugee adolescents; $\mid \mathrm{A}$ = first- and second-generation immigrant adolescents.

surface plot created with R 4.0.4 (see Figure E3 in Electronic Supplementary Material, ESM 1, for an animated version). In addition, a moderated regression analysis with the group variable as a second-order moderator can be found in ESM 1 (Table E1). Prior to the analysis, variables involved in the interaction terms were mean-centered, and homoscedasticity was tested with the modified BreuschPagan test, $\chi^{2}=.01, p=.993$.

To examine group differences in the association between religiosity and internalizing symptoms indirectly explained by levels of acculturation orientations, moderated firststage mediation analyses were conducted using IBM Amos 27, taking into account possible age effects (H2). Conditional indirect effects were tested by percentile bootstrapping based on 10,000 resamples and the index of moderated mediation, which tests whether indirect effects differ between groups. According to Preacher et al. (2007), the same type of model calculation with a sample size of $N=100$ and mean effect size (regression coefficients $=.39$ ) yields a power of $95 \%$.

To ensure that questionnaires measure the same construct across groups, measurement invariance was assessed. At least metric invariance was observed for religiosity (see ESM 1) as well as for acculturation orientations and mental health (see EL-Awad et al., 2021).

\section{Results}

\section{Religiosity as Buffering Factor on the Association Between Post-Traumatic Stress and Internalizing Symptoms in Comparison Between Refugee and Immigrant-Origin Youth (H1)}

Refugee adolescents suffered more from PTEs than IA, $t(131)=2.75, p=.007$. In total, 117 participants $(88 \%)$ reported having experienced at least one PTE, $n_{\mathrm{RA}}=69$ $\left(M_{\mathrm{PTE}}=5.62, S D_{\mathrm{PTE}}=3.36\right), n_{\mathrm{IA}}=48\left(M_{\mathrm{PTE}}=4.50, S D_{\mathrm{PTE}}\right.$ $=2.63)$. War-related PTEs were reported from most RA (77\%), while IA (83\%) reported PTEs related to violence within the family or in the own community. Table 2 gives information on descriptive statistics and bivariate Pearson correlations for internalizing symptoms, religiosity, and PTEs in RA and IA. Both groups did not differ regarding internalizing symptoms, $t(131)=0.90, p=.371$. Internalizing symptoms correlated positively with PTEs among all participants $(r=.36, p<.001)$, in RA $(r=.26, p=.028)$ and in IA $(r=.52, p<.001)$. Religiosity was significantly more prevalent in RA $\left(M_{\mathrm{RA}}=0.28, S D_{\mathrm{RA}}=0.84\right)$ than in IA $\left(M_{\mathrm{IA}}=\right.$ $\left.-0.35, S D_{\mathrm{IA}}=0.87\right), t(131)=4.23, p<.001$. 
Table 2. Descriptive statistics and correlations for considered model variables

\begin{tabular}{|c|c|c|c|c|c|c|c|c|c|}
\hline & M & $S D$ & 1 & 2 & 3 & 4 & 5 & 6 & 7 \\
\hline \multicolumn{10}{|l|}{ Total $(N=133)$} \\
\hline 1. Internalizing symptoms & 43.29 & 13.62 & - & -.12 & $.20 *$ & $.38 * * *$ & $-.22^{\star}$ & -.02 & $.36 * \star \star$ \\
\hline 2. Religiosity & 0.00 & 1.00 & & - & $.30 * \star \star$ & -.09 & -.08 & .14 & .16 \\
\hline 3. Separation & 2.29 & 0.54 & & & - & $.28^{\star \star}$ & $-.17 \star$ & -.03 & $.15^{\star}$ \\
\hline 4. Marginalization & 1.91 & 0.65 & & & & - & -.07 & $.19 *$ & $.16^{\star}$ \\
\hline 5. Integration & 3.12 & 0.47 & & & & & - & $.42 * \star \star$ & -.11 \\
\hline 6. Assimilation & 2.50 & 0.59 & & & & & & - & .11 \\
\hline 7. PTE & 4.46 & 3.41 & & & & & & & - \\
\hline \multicolumn{10}{|l|}{$\mathrm{RA}(n=74)$} \\
\hline 1. Internalizing symptoms & 43.84 & 15.11 & - & -.19 & .16 & $.36^{\star \star \star}$ & $-.28 *$ & -.02 & $.26^{\star}$ \\
\hline 2. Religiosity & 0.28 & 0.84 & & - & .10 & -.22 & -.05 & .06 & .03 \\
\hline 3. Separation & 2.40 & 0.5 & & & - & $.28^{\star}$ & -.09 & -.19 & -.09 \\
\hline 4. Marginalization & 1.91 & 0.62 & & & & - & -.06 & .22 & .08 \\
\hline 5. Integration & 3.10 & 0.44 & & & & & - & $.48 * \star \star$ & -.11 \\
\hline 6. Assimilation & 2.71 & 0.48 & & & & & & - & .05 \\
\hline 7. PTE & 5.24 & 3.54 & & & & & & & - \\
\hline \multicolumn{10}{|l|}{ IA $(n=59)$} \\
\hline 1. Internalizing symptoms & 42.69 & 12.25 & - & -.11 & $.23 * \star$ & $.41 * \star \star$ & -.10 & -.05 & 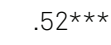 \\
\hline 2. Religiosity & -0.35 & 0.87 & & - & $.42^{\star \star \star}$ & .05 & -.12 & .01 & .18 \\
\hline 3. Separation & 2.15 & 0.51 & & & - & .20 & $-.35^{\star}$ & -.12 & $.44^{* \star *}$ \\
\hline 4. Marginalization & 1.90 & 0.66 & & & & - & -.23 & .08 & $.43^{* * *}$ \\
\hline 5. Integration & 3.12 & 0.51 & & & & & - & $.40 * \star$ & -.04 \\
\hline 6. Assimilation & 2.21 & 0.57 & & & & & & - & .07 \\
\hline 7. PTE & 3.65 & 2.95 & & & & & & & - \\
\hline
\end{tabular}

Note. $\mathrm{RA}=$ refugee adolescents; $\mathrm{IA}$ = first- and second-generation immigrant adolescents; $\mathrm{PTE}=\mathrm{CATS}$ potentially traumatic events; Religiosity = DUREL score. ${ }^{\star} p<.05 ;{ }^{* \star} p<.01 ;{ }^{* *} p<.001$.

Contrary to the hypothesis, religiosity did not buffer against negative mental health consequences of PTEs, as there was no significant interaction of PTEs and religiosity (Table 3). Moreover, Figure 2 shows (as does the statistical analysis; see Table E1 in the ESM 1) that there was no group-specific effect on mental health since the surfaces seem to be similarly located in space (no confirmation of H1b). Instead, a positive main effect for religiosity on internalizing symptoms is visible in the plot (skewness of the surface toward the $z$-axis) and could also be determined in the regression analysis. A post hoc sensitivity analysis showed that this was even more evident after participants without any PTEs $\left(n_{\mathrm{RA}-\mathrm{NO}-\mathrm{PTE}}=5, n_{\mathrm{IA}-\mathrm{NO}-\mathrm{PTE}}=11\right)$ were excluded from the analysis, $b_{\text {religiosity }}=-4.56$, $t(111)=-3.21,95 \%$ CI $[-7.37,-1.75], p=.001 ; R^{2}=.23$, $F(5,111)=6.59, p<.001$. Among those who had not experienced PTEs and were previously excluded from the sensitivity analysis, religiosity was about $0.68 S D$ below the group average.

However, when the analysis was repeated with individual religious dimensions (see Table E2 in ESM 1), more differentiated results emerged: regarding religious activity, a significant three-way interaction indicated a group-specific buffering effect of religious activity (see Figure E1 in ESM 1), in addition to the main effect. Religiously active RA reported fewer internalizing symptoms after experiencing more PTE, while religiously active IA were more likely to suffer more internalizing symptoms.

\section{Indirect Association Between Religiosity and Internalizing Symptoms via Acculturation Orientations (H2)}

Bivariate Pearson correlations across all participants (see Table 2) revealed an association of elevated internalizing symptoms with separation $(r=.20, p=.021)$ and marginalization $(r=.38, p<.001)$, while for integration the opposite was the case $(r=-.22, p=.019)$. There was no significant mental health association for assimilation. Moreover, a positive correlation between separation and religiosity $(r=.30$, $p<.001)$ could be identified. However, an examination within the groups showed that the correlation was mainly triggered by IA $(r=.42, p<.001)$, as it was not significant in RA. Regarding the correlation between religiosity and marginalization, no intergroup correlation was observed, 
Table 3. Moderation effect of religiosity on the relationship between potentially traumatic events and internalizing symptoms

\begin{tabular}{|c|c|c|c|c|c|c|}
\hline \multirow[b]{2}{*}{ Predictor } & \multirow[b]{2}{*}{$b$} & \multicolumn{2}{|c|}{$95 \% \mathrm{Cl}$ for $b^{a}$} & \multirow[b]{2}{*}{$S E^{a}$} & \multirow[b]{2}{*}{$t$} & \multirow[b]{2}{*}{$p$} \\
\hline & & Lower & Upper & & & \\
\hline Age & -0.23 & -1.50 & 1.04 & 0.64 & -0.35 & .725 \\
\hline $\mathrm{RE}$ & -3.83 & -6.51 & -1.14 & 1.36 & -2.82 & .005 \\
\hline PTE & 1.69 & 1.04 & 2.35 & 0.33 & 5.12 & $<.001$ \\
\hline Group & -1.25 & -5.83 & 3.33 & 2.31 & -0.54 & .589 \\
\hline $\mathrm{PTE} \times \mathrm{RE}$ & -0.40 & -1.16 & 0.37 & 0.39 & -1.02 & .308 \\
\hline
\end{tabular}

Note. $N=133$. Model fit $R^{2}=.21, F(5,127)=6.69, p<.001$. Group = binary variable $(0=$ refugee adolescents, $1=$ first- and second-generation immigrant

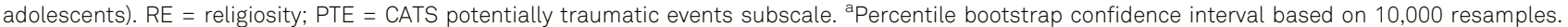

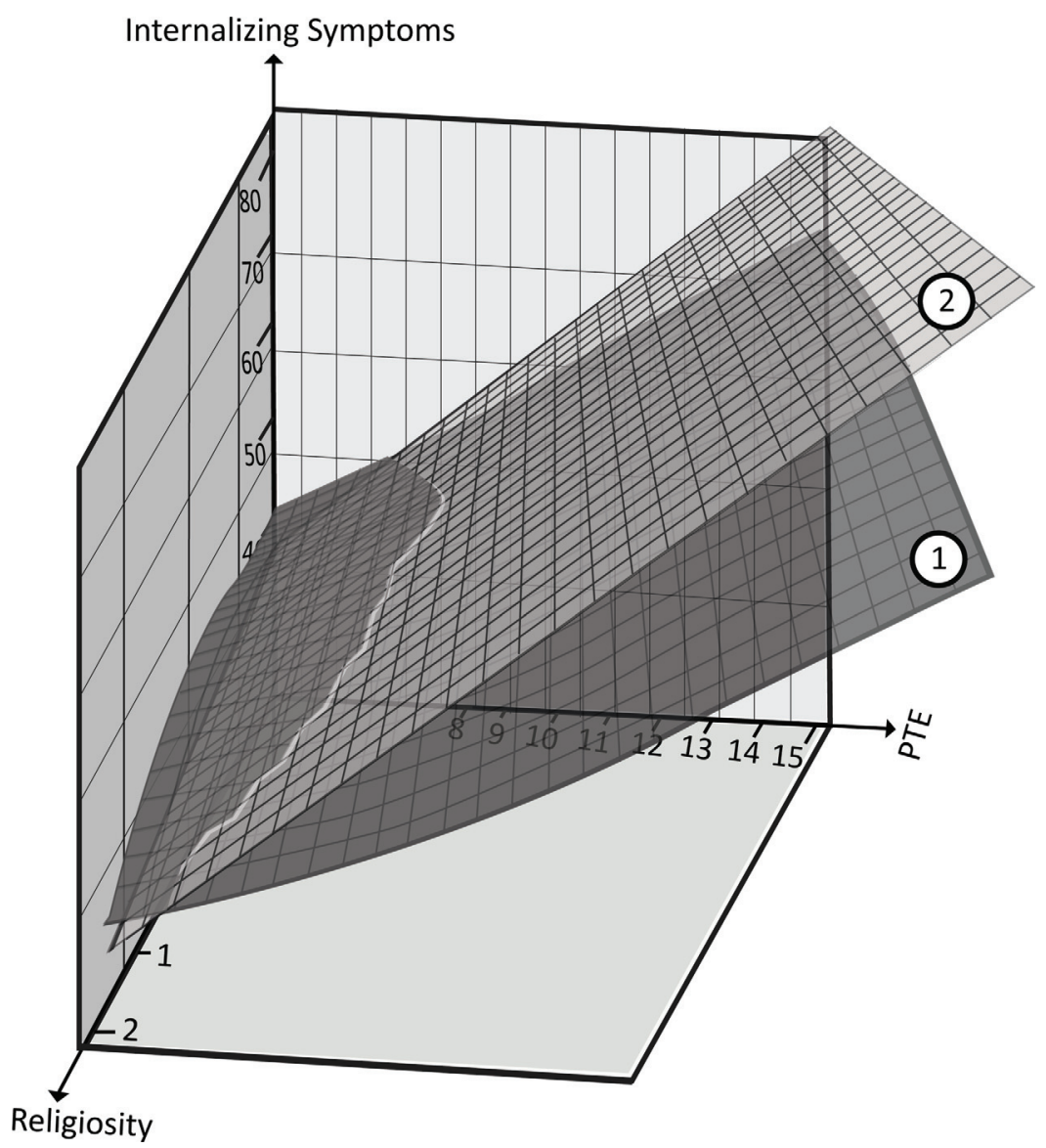

Figure 2. 3D surface plot on the relationship between potentially traumatic events, religiosity, and internalizing symptoms. $1=$ refugee adolescents; 2 = first- and secondgeneration immigrants; $\mathrm{PTE}=$ potential traumatic events. Scales ranges: religiosity $[2,-1.5]$, internalizing symptoms $[80,20]$, PTE $[15,0]$.

but it was visible that it was negative for RA, although not significant, $r=-.22, p=.056$.

These findings were consistent with the results of the mediation analyses (Figure 3 ). Although a negative association between marginalization and mental health could be identified, only the mediation model with separation was significant in IA but not in RA, supporting Hypothesis $2 b$. In this respect, religiosity seemed to be related to greater values regarding separation in IA, with separation being associated with more internalizing symptoms, while this was not relevant for RA.

Nevertheless, post hoc analysis with intrinsic religiosity (see Figure E2 in ESM 1) showed a significant indirect effect for RA, but not for IA, indicating that stronger intrinsic religiosity was associated with less marginalization and less internalizing symptoms. The exploratory mediation analyses with integration and assimilation yielded nonsignificant results, although a favorable direct effect of integration on internalizing symptoms was observed.

\section{Discussion}

This study examined the role of religiosity on resilience in RA and IA. While religiosity is generally considered beneficial when traumatic experiences have occurred, the present 
(A)

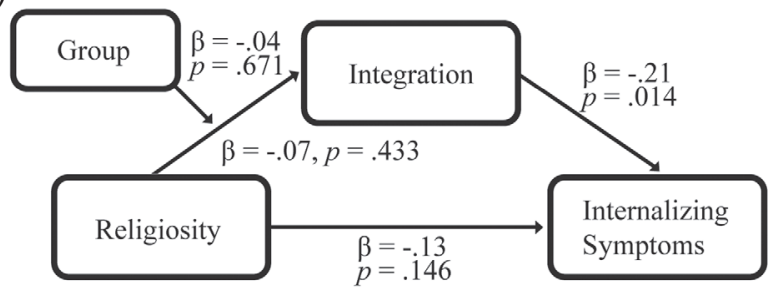

Note. $C F I=.97 ; S R M R=.029$. Conditional Indirect Effect for RA: $b=0.13, p=.542$; for IA: $b=0.39, p=.303$. Index of Moderated Mediation: $b=0.26, p=.569$.

(C)

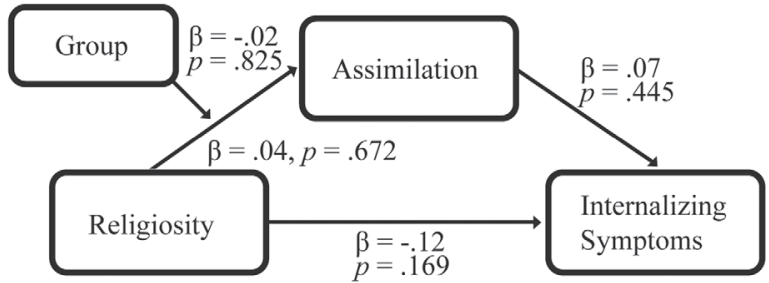

Note. $C F I=.99 ; S R M R=.024$. Conditional Indirect Effect for RA: $b=0.06, p=.369$; for IA: $b=0.02, p=.721$. Index of Moderated Mediation: $b=-0.04, p=.490$.
(B)

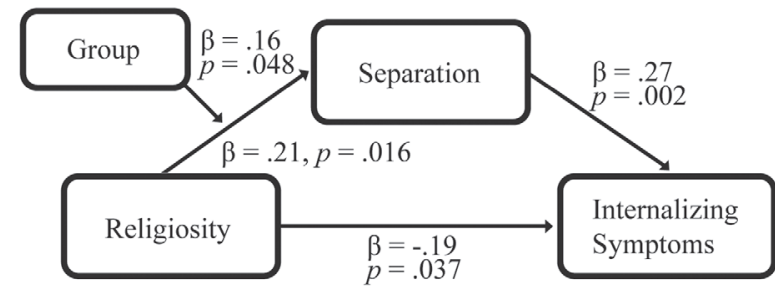

Note. $C F I=.99 ; S R M R=.018$. Conditional Indirect Effect for RA: $b=0.29, p=.647$; for IA: $b=1.67, p=.006$. Index of Moderated Mediation: $b=1.38, p=.034$.

(D)

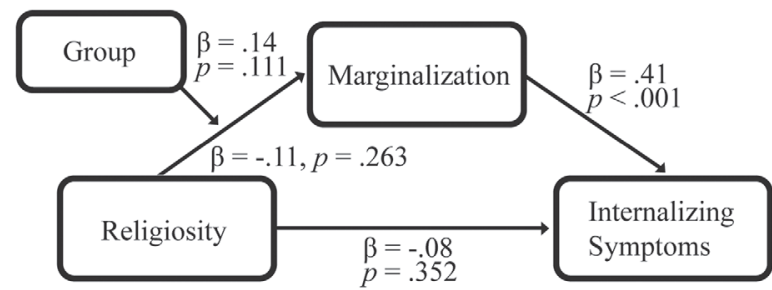

Note. $C F I=.99 ; S R M R=.023$. Conditional Indirect Effect for RA: $b=-1.43, p=.051$; for IA: $b=0.35, p=.664$. Index of Moderated Mediation: $b=1.78, p=.079$.

Figure 3. First-stage moderated mediation models examining group-specific differences among RA and IA concerning indirect effects of acculturation orientations with (A) integration, (B) separation, (C) assimilation, and (D) marginalization on the relationship between religiosity and internalizing symptoms.

findings suggest that context may be crucial to the effectiveness of religiosity as a protective factor. Migration related contextual factors influence the extent to which religiosity is associated with mental health.

\section{Religiosity in the Context of Traumatic Experiences}

It was hypothesized that religiosity would be more important for resilience in RA than IA because RA may have experienced more PTEs. Considering religiosity as a buffering factor against stress resulting from traumatic experiences, the findings did not show an interaction between religiosity and the number of PTEs on internalizing symptoms (H1a) nor any group differences regarding this relationship (H1b). Instead, higher levels of religiosity were directly associated with lower levels of internalizing symptoms, independent of PTEs. Religiosity was as important for resilience for youth who had experienced one PTE as for those who had experienced multiple PTEs, suggesting that perceived severity may be a better predictor than the number of events. In the case of RA, the war experience may already trigger high levels of post-traumatic stress and thus might not be quantitatively comparable to other PTEs.
This finding is consistent with previous research on religiosity and mental health showing that religiosity positively impacts mental health across multiple groups (Power \& McKinney, 2014), although research has produced significant results demonstrating both direct effects and buffering effects (Smith et al., 2004). Indeed, the present study demonstrated an initial buffering effect of religious activity (see Table E2 in ESM 1). High religious activity was associated with low internalizing symptomatology the more PTEs occurred in RA, whereas the opposite was true in IA.

\section{Religiosity in the Context of Acculturation}

Looking at the relationship between religiosity and mental health through the lens of acculturation, differences between groups emerge. While intrinsically religious RA tended to feel less marginalized and perceive fewer internalizing symptoms, this indirect relationship was nonsignificant for IA. More religious IA were more likely to be separated (see also Figure E2 in ESM 1, as religious activity, in particular, was crucial in this context) and associated with more internalizing symptoms than less religious IA. This is consistent with the inverse interaction regarding religious activity and PTEs in IA compared with RA (see H1). 
It could even be that the different acculturation context is responsible for the effect, although the resilience-promoting function of religiosity is maintained among those who experienced PTEs. Furthermore, this suggests that social and identity needs shape the relationship between religiosity and mental health differently depending on group-specific challenges.

Refugees from the Middle East suffer from social isolation, language barriers, hopelessness, and discrimination in Western societies (Yako \& Biswas, 2014). Some of these burdens are certainly due to the short length of stay but could also apply equally to first- and second-generation IA, such as discrimination in hiring and other career areas (Carlsson, 2010). Other burdens that appear to be more relevant to RA marginalization are more related to post-traumatic stress, such as hopelessness (Fazel et al., 2012) or to anti-refugee policies and inadequate refugee housing that lead to social exclusion (Leiler et al., 2019). A negative relationship between intrinsic religiosity and marginalization suggests that religious RA may succeed in coping with these forms of stress, for example, by placing their life situation in God's hands (i.e., relying on God's will and waiting for it to happen) to gain control through passive religious deferral (Ahmadi et al., 2019). In addition, religion may play an important role for Muslim RA in non-Muslim countries because it could influence the quality of contact within the group, which is often the only source of social interaction in a new environment (Allen, 2010). However, in irreligious RA, establishing group contact might be more complicated than in religious RA.

In the case of IA from the Middle East, mental health problems appear to be associated with separation (Brand et al., 2017). For IA of the 1.5 generation and their families, educational or career goals are often the reason for their migration, but these are difficult to achieve without integration into the majority culture (Schwartz et al., 2010). IA of the 1.5th and second generation have already been integrated into majority society since childhood or birth and may see their parents' culture of origin as a secondary source for identity formation. This may be particularly the case if they have experienced rejection or discrimination in the majority society (Vedder et al., 2007).

Religiosity is likely associated with the culture of origin when it is a dominant part of cultural life in the home country but not in the host country, as is the case for Muslim IA in Western countries (Byng, 2017). The incompatibility between individual goals related to career and religious worship may force Muslim IA to separate, preventing them from fulfilling their developmental tasks and expectations (Roth, 2020; Statham \& Tillie, 2016). Moreover, anti-Muslim sentiments in Germany and other European societies due to fears of terrorist attacks may reduce the opportunity for Muslim youth to develop a healthy bicultural identity while promoting separation in Muslim minority communities (Müller, 2017).

\section{Religiosity in the Context of Unaccompanied Refugee Adolescents}

Parents are often the primary source, encouraging and controlling the development of religiosity through techniques such as spiritual modeling or social channeling (King \& Roeser, 2009). Adolescents unconsciously acquire and retain religious behaviors by observing the religious practices of adults close to them. In addition, parents introduce them to religious, social circles and activities. Thus, separated youth could be more limited to majority society conditions. Therefore, although unaccompanied refugees from the Middle East, like accompanied refugees, have grown up with an Islamic identity, it is possible that in the case of unaccompanied refugees, this may be more likely to be challenged by Western-oriented social structures (Morgan, 2018). Post hoc analyses of the present study support this assumption, as unaccompanied RA were significantly less religious than accompanied RA, $t(72)=2.85, p=.006$. However, consistent with previous results (e.g., Ní Raghallaigh, 2011), there were no differences between accompanied and unaccompanied RA with regard to the associations between religiosity and mental health (see Table E3 in ESM 1).

\section{Implications for Resilience Research: The Importance of Context}

Although during the last decade research on resilience acknowledged the importance of different contexts and argued that protective effects should not be interpreted as inherent to protective factors (Masten, 2014), research on context effects of potentially protective factors has been scarce. In addition, if resilience relies on compensatory processes, there could be maladaptive side effects. The results of the present study highlight the importance of context effects and are the first to demonstrate that a protective factor (i.e., religiosity) in one context (e.g., traumatic events) could have negative side effects in another context (e.g., acculturation) or another group of people (i.e., RA vs. IA). As Ungar (2011) noted: "The study of resilience should involve context first and the [individual] second". However, so far, no systematic analyses of contexts describing the situation of (Muslim) RA and IA in Western European countries exist, and only little is known about differences in contexts between RA and IA (see EL-Awad et al., 2021 for differences regarding post-migration stressors). Hence, future studies need to systematically analyze and contrast the environmental contexts of RA and IA, including various 
levels as families, neighborhoods, or the community (see Suárez-Orozco et al., 2018).

\section{Implications for Future Research, Limitations, and Conclusions}

Identifying protective factors for refugee mental health is essential for developing appropriate support programs (EL-Awad et al., 2017). Because both pre-migration stress and acculturative stress contribute to refugees' mental health (Ellis et al., 2010), it is critical to identify intervention targets that, at best, buffer both types of stressors and do not protect against one type of stressor (e.g., pre-migration trauma), while reinforcing the other (e.g., acculturative stress). Furthermore, it is important to determine whether protective factors operate in the same way at each point in the acculturation process in order to make resilience programs as effective as possible. This is the first study to examine religiosity as a protective factor regarding both the experience of PTEs and acculturation processes in RA and IA. While religiosity appears to protect from PTEs and marginalization in the case of Middle Eastern RA, future studies should also target other coping strategies. Coping strategies may differ in individuals as PTEs took place mainly in the past, whereas acculturation occurs in the present and future (Sagbakken et al., 2020). As religiosity has different associations with mental health and resilience in RA and IA, longitudinal studies are needed to detect (a) when, (b) for whom, and (c) in which contexts these differences occur.

Furthermore, the role of religiosity may vary depending on the cultural gap between the host culture and the culture of origin (Schwartz et al., 2010). This includes whether religiosity is widespread in the host country or held only by a minority and consequently facilitates or hinders social interaction within the host society (Yako \& Biswas, 2014). Moreover, moderate religious societies may establish more contact with refugee populations than secular societies, regardless of the refugee's religious affiliation (Steinmann, 2020). It is also conceivable that attitudes on the part of majority society toward the social integration of religious minority members differ across microsystems (e.g., among teachers in school settings), which could affect the association between religiosity and acculturation orientations among youth. Therefore, future studies should focus on different countries (e.g., Syrian refugees in Germany and Turkey) and different microsystems (e.g., school environments).

In addition, results from this study are limited to males and the group of refugees who mainly arrived in Germany in 2015 and 2016. Although males were the predominant group of RA in Germany, there are now a substantial number of female RA who should be considered in future studies (Federal Office for Migration and Refugees, 2020). Because female RA generally have poorer mental health outcomes than males, depending on their cultural background (Porter \& Haslam, 2005), it is possible that these differences also have an impact on the relationship between religiosity and mental health. However, the relationship between religiosity and mental health may be more significant for male adolescents than for their female peers (Cotton \& Berry, 2007). In addition, most RA arrived in Germany either through the Balkan route or via the Mediterranean Sea. They often had to pay traffickers. In this context, families may have selected particularly resistant family members to send ahead and prepare for later family reunification in the host country. Therefore, it cannot be ruled out that the links between mental health and religiosity are different for other refugee groups who, for example, migrated by plane or did not continue to Germany but stayed in Southern Europe or Turkey.

Finally, the results of the present study do not allow for causal interpretations due to the cross-sectional design. Although RA in particular represents an extremely difficult group to reach, a larger sample size would be more advantageous against potential statistical artifacts and more representative. Moreover, power issues in statistical tests due to the small sample size apply. In particular, this could be the case when testing group-specific effects with regard to the moderation by religiosity. It should, therefore, be taken into account that group-specific moderation effects, as already demonstrated for religious activity in the context of the present study, could be relevant in larger samples.

In conclusion, religiosity is important for RA and IA resilience by protecting against the consequences of experienced PTEs, but associations of religiosity and mental health, in general, might depend on the role of religiosity in a person's acculturation orientation. Therefore, while religion might not always be a resource in support programs, it certainly should not be ignored.

\section{Electronic Supplementary Materials}

The electronic supplementary material is available with the online version of the article at https://doi.org/ $10.1027 / 2512-8442 / \mathrm{a} 000100$

ESM 1. Results of additional (post hoc) analyses

\section{References}

Adedoyin, A. C., Bobbie, C., Griffin, M., Adedoyin, O. O., Ahmad, M., Nobles, C., \& Neeland, K. (2016). Religious coping strategies among traumatized African refugees in the United States: A systematic review. Social Work and Christianity, 43(1), 95-107. 
Ahmadi, F., Mohamed Hussin, N. A., \& Mohammad, M. T. (2019). Religion, culture and meaning-making coping: A study among cancer patients in Malaysia. Journal of Religion and Health, 58(6), 1909-1924. https://doi.org/10.1007/s10943-018-0636-9

Allen, R. (2010). The bonding and bridging roles of religious institutions for refugees in a non-gateway context. Ethnic and Racial Studies, 33(6), 1049-1068. https://doi.org/10.1080/ 01419870903118130

Allport, G. W., \& Ross, J. M. (1967). Personal religious orientation and prejudice. Journal of Personality and Social Psychology, 5(4), 432-443. https://doi.org/10.1037/h0021212

Bean, T., Derluyn, I., Eurelings-Bontekoe, E., Broekaert, E., \& Spinhoven, P. (2007). Validation of the multiple language versions of the Hopkins Symptom Checklist-37 for refugee adolescents. Adolescence, 42(165), 51-71.

Berry, J. W. (1997). Immigration, acculturation, and adaptation. Applied Psychology, 46(1), 5-34. https://doi.org/10.1111/ j.1464-0597.1997.tb01087.x

Brand, T., Samkange-Zeeb, F., Ellert, U., Keil, T., Krist, L., Dragano, N., Jöckel, K.-H., Razum, O., Reiss, K., Greiser, K. H., Zimmermann, H., Becher, H., \& Zeeb, H. (2017). Acculturation and health-related quality of life: Results from the German National Cohort migrant feasibility study. International Journal of Public Health, 62(5), 521-529. https://doi.org/10.1007/ s00038-017-0957-6

Brislin, R. W. (1970). Back-translation for cross-cultural research. Journal of Cross-Cultural Psychology, 1(3), 185-216. https:// doi.org/10.1177/135910457000100301

Byng, M. (2017). Transnationalism among second-generation Muslim Americans: Being and belonging in their transnational social field. Social Sciences, 6(4), Article 131. https://doi.org/ 10.3390/socsci6040131

Carlsson, M. (2010). Experimental evidence of discrimination in the hiring of first- and second-generation immigrants. Labour, 24(3), 263-278. https://doi.org/10.1111/j.1467-9914.2010.00482.x

Cohen, A. B. (2009). Many forms of culture. The American Psychologist, 64(3), 194-204. https://doi.org/10.1037/a0015308

Cotton, S., \& Berry, D. (2007). Religiosity, spirituality, and adolescent sexuality. Adolescent Medicine: State of the Art Reviews, 18(3), 471-483, vi.

Dempster, A. P., Laird, N. M., \& Rubin, D. B. (1977). Maximum likelihood from incomplete data via the EM algorithm. Journal of the Royal Statistical Society: Series B (Methodological), 39(1), 1-22. https://doi.org/10.1111/j.2517-6161.1977.tb01600.x

EL-Awad, U., Fathi, A., Petermann, F., \& Reinelt, T. (2017). Promoting mental health in unaccompanied refugee minors: Recommendations for primary support programs. Brain Sciences, 7(11), 146. https://doi.org/10.3390/brainsci7110146

EL-Awad, U., Fathi, A., Vasileva, M., Petermann, F., \& Reinelt, T. (2021). Acculturation orientations and mental health when facing post-migration stress: Differences between unaccompanied and accompanied male Middle Eastern refugee adolescents, first-and second-generation immigrant and native peers in Germany. International Journal of Intercultural Relations, 82, 232-246. https://doi.org/10.1016/j.ijintrel.2021.04.002

Ellis, B. H., MacDonald, H. Z., Klunk-Gillis, J., Lincoln, A., Strunin, L., \& Cabral, H. J. (2010). Discrimination and mental health among Somali refugee adolescents: The role of acculturation and gender. The American Journal of Orthopsychiatry, 80(4), 564-575. https://doi.org/10.1111/j.1939-0025.2010.01061.x

Fazel, M., Reed, R. V., Panter-Brick, C., \& Stein, A. (2012). Mental health of displaced and refugee children resettled in high-income countries: Risk and protective factors. The Lancet, 379(9812), 266-282. https://doi.org/10.1016/s0140-6736(11)60051-2

Federal Office for Migration and Refugees. (2017). Das Bundesamt in Zahlen 2016: Asyl, Migration und Integration [The federal office in numbers: Asylum, migration, and integration]. https:// www.bamf.de/SharedDocs/Anlagen/DE/Statistik/Bundesamtin Zahlen/bundesamt-in-zahlen-2016.pdf

Federal Office for Migration and Refugees. (2020). Das Bundesamt in Zahlen 2019 - Asyl, Migration und Integration [The federal office in numbers 2019 - Asylum, migration, and integration]. https://www.bamf.de/SharedDocs/Anlagen/DE/Statistik/ BundesamtinZahlen/bundesamt-in-zahlen-2019.pdf?__blob= publicationFile\& $v=5$

Finch, B. K., \& Vega, W. A. (2003). Acculturation stress, social support, and self-rated health among Latinos in California. Journal of Immigrant Health, 5(3), 109-117. https://doi.org/ 10.1023/A:1023987717921

Giuliani, C., Tagliabue, S., \& Regalia, C. (2018). Psychological well-being, multiple identities, and discrimination among first and second generation immigrant Muslims. Europe's Journal of Psychology, 14, 66-87. https://doi.org/10.5964/ ejop.v14i1.1434

Gregg, G. S. (2005). The Middle East: A cultural psychology. Oxford University Press.

Güngör, D., Fleischmann, F., Phalet, K., \& Maliepaard, M. (2013). Contextualizing religious acculturation. European Psychologist, 18(3), 203-214. https://doi.org/10.1027/1016-9040/a000162

Hodes, M., Jagdev, D., Chandra, N., \& Cunniff, A. (2008). Risk and resilience for psychological distress amongst unaccompanied asylum seeking adolescents. Journal of Child Psychology and Psychiatry, 49, 723-732. https://doi.org/10.1111/j.14697610.2008.01912.x

King, P. E., \& Roeser, R. W. (2009). Religion and spirituality in adolescent development. In R. M. Lerner \& L. D. Steinberg (Eds.), Handbook of adolescent psychology (3rd ed., pp. 435478). Wiley. https://doi.org/10.1002/9780470479193.adlpsy 001014

Koenig, H. G., \& Büssing, A. (2010). The Duke University Religion Index (DUREL): A five-item measure for use in epidemological studies. Religions, 1(1), 78-85. https://doi.org/10.3390/ rel1010078

Kumaraswamy, P. R. (2006). Who am I? The identity crisis in the Middle East. Middle East Review of International Affairs, 10, $63-73$.

Kunst, J. R., \& Sam, D. L. (2014). "It's on time that they assimilate" - differential acculturation expectations towards first and second generation immigrants. International Journal of Intercultural Relations, 39, 188-195. https://doi.org/10.1016/j. ijintrel.2013.10.007

Leiler, A., Bjärtå, A., Ekdahl, J., \& Wasteson, E. (2019). Mental health and quality of life among asylum seekers and refugees living in refugee housing facilities in Sweden. Social Psychiatry and Psychiatric Epidemiology, 54(5), 543-551. https://doi.org/ 10.1007/s00127-018-1651-6

Lincoln, A. K., Lazarevic, V., White, M. T., \& Ellis, B. H. (2016). The impact of acculturation style and acculturative hassles on the mental health of Somali adolescent refugees. Journal of Immigrant and Minority Health, 18(4), 771-778. https://doi. org/10.1007/s10903-015-0232-y

Majumder, P., O'Reilly, M., Karim, K., \& Vostanis, P. (2015). "This doctor, I not trust him, I'm not safe": The perceptions of mental health and services by unaccompanied refugee adolescents. The International Journal of Social Psychiatry, 61(2), 129-136. https://doi.org/10.1177/0020764014537236

Masten, A. S. (2014). Global perspectives on resilience in children and youth. Child Development, 85(1), 6-20. https://doi.org/ $10.1111 /$ cdev. 12205

Morgan, J. (2018). Choosing Heresy: How Muslim-background unaccompanied refugee minors do identity and belonging in the church of Sweden. Lunds University Press. 
Müller, T. (2017). Constructing cultural borders: Depictions of Muslim refugees in British and German media. Zeitschrift für Vergleichende Politikwissenschaft, 12(1), 263-277. https://doi. org/10.1007/s12286-017-0361-x

Pargament, K. I. (2011). Religion and coping: The current state of knowledge. In S. Folkman (Ed.), Oxford library of psychology. The Oxford handbook of stress, health, and coping (pp. 1-38). Oxford University Press. https://doi.org/10.1093/oxfordhb/ 9780195375343.013.0014

Pargament, K. I., Ensing, D. S., Falgout, K., Olsen, H., Reilly, B., van Haitsma, K., \& Warren, R. (1990). God help me: (I): Religious coping efforts as predictors of the outcomes to significant negative life events. American Journal of Community Psychology, 18(6), 793-824. https://doi.org/10.1007/BF00938065

Porter, M., \& Haslam, N. (2005). Predisplacement and postdisplacement factors associated with mental health of refugees and internally displaced persons: A meta-analysis. Journal of the American Medical Association, 294(5), 602-612. https://doi. org/10.1001/jama.294.5.602

Power, L., \& McKinney, C. (2014). The effects of religiosity on psychopathology in emerging adults: Intrinsic versus extrinsic religiosity. Journal of Religion and Health, 53(5), 1529-1538. https://doi.org/10.1007/s10943-013-9744-8

Preacher, K. J., Rucker, D. D., \& Hayes, A. F. (2007). Addressing moderated mediation hypotheses: Theory, methods, and prescriptions. Multivariate Behavioral Research, 42(1), 185-227. https://doi.org/10.1080/00273170701341316

Ní Raghallaigh, M. (2011). Religion in the lives of unaccompanied minors: An available and compelling coping resource. British Journal of Social Work, 41(3), 539-556. https://doi.org/ 10.1093/bjsw/bcq136

Reinelt, T., Schipper, M., \& Petermann, F. (2016). Different pathways to resilience: On the utility of the resilience concept in clinical child psychology and child psychiatry. Kindheit und Entwicklung, 25(3), 189-199. https://doi.org/10.1026/09425403/a000204

Roth, T. (2020). The role of religion, religiousness and religious participation in the school-to-work transition in Germany. Journal of Ethnic and Migration Studies, 46(17), 3580-3602. https://doi.org/10.1080/1369183X.2019.1620414

Sachser, C., Berliner, L., Holt, T., Jensen, T. K., Jungbluth, N., Risch, E., Rosner, R., \& Goldbeck, L. (2017). International development and psychometric properties of the Child and Adolescent Trauma Screen (CATS). Journal of Affective Disorders, 210, 189-195. https://doi.org/10.1016/j.jad.2016. 12.040

Sagbakken, M., Bregård, I. M., \& Varvin, S. (2020). The past, the present, and the future: A qualitative study exploring how refugees' experience of time influences their mental health and well-being. Frontiers in Sociology, 5, Article 46. https://doi.org/ 10.3389/fsoc. 2020.00046

Schwartz, S. J., Unger, J. B., Zamboanga, B. L., \& Szapocznik, J. (2010). Rethinking the concept of acculturation: Implications for theory and research. The American Psychologist, 65(4), 237251. https://doi.org/10.1037/a0019330

Shortz, J. L., \& Worthington, E. L. (1994). Young adults' recall of religiosity, attributions, and coping in parental divorce. Journal for the Scientific Study of Religion, 33(2), 172-179. https://doi. org/10.2307/1386603

Smith, T. B., McCullough, M. E., \& Poll, J. (2003). Religiousness and depression: Evidence for a main effect and the moderating influence of stressful life events. Psychological Bulletin, 129(4), 614-636. https://doi.org/10.1037/0033-2909.129.4.614

Statham, P., \& Tillie, J. (2016). Muslims in their European societies of settlement: A comparative agenda for empirical research on socio-cultural integration across countries and groups. Journal of Ethnic and Migration Studies, 42(2), 177-196. https://doi. org/10.1080/1369183x.2015.1127637

Steinmann, J.-P. (2020). Religiosity and natives' social contact with new refugees. Explaining differences between East and West Germany. International Journal of Intercultural Relations, 74, 189-205. https://doi.org/10.1016/j.ijintrel.2019.10.007

Suárez-Orozco, C., Motti-Stefanidi, F., Marks, A., \& Katsiaficas, D. (2018). An integrative risk and resilience model for understanding the adaptation of immigrant-origin children and youth. The American Psychologist, 73(6), 781-796. https://doi. org/10.1037/amp0000265

Tagay, S., Lindner, M., Beckmann, M., Krebs, S., Hess, S., \& Schlottbohm, E. (2013). Essen Migration Inventory (EMI) [Questionnaire]. LVR-Klinikum.

Ungar, M. (2011). The social ecology of resilience: Addressing contextual and cultural ambiguity of a nascent construct. American Journal of Orthopsychiatry, 81(1), 1-17. https://doi. org/10.1111/j.1939-0025.2010.01067.x

Vedder, P., Sam, D. L., \& Liebkind, K. (2007). The acculturation and adaptation of Turkish adolescents in North-Western Europe. Applied Developmental Science, 11(3), 126-136. https://doi. org/10.1080/10888690701454617

Yako, R. M., \& Biswas, B. (2014). "We came to this country for the future of our children. We have no future": Acculturative stress among Iraqi refugees in the United States. International Journal of Intercultural Relations, 38, 133-141. https://doi.org/ 10.1016/j.ijintrel.2013.08.003

\section{History}

Received February 11, 2021

Revision received September 6, 2021

Accepted September 7, 2021

Published online January 28, 2022

\section{Acknowledgments}

We thank Aysan Amirghiyasvand, Miriam Delgado, Jan Philipp Kehr-Ritz, Gloria Lew, Neele Penning, Baheschtae Said, Nora Kimberly Scholz and Thore Würger for their help with data collection. We also thank Helfer HBF e.V. and Majd Awad for their support with the acquisition of participants. The manuscript was written during the lifetime of Franz Petermann, who was substantially involved in the implementation and conception of the work.

\section{Conflict of Interest}

The authors declare that there is no conflict of interest.

\section{Publication Ethics}

A local ethics committee approved the study.

\section{Open Data}

The data that support the findings of this study are confidential but available from the corresponding author upon reasonable request.

\section{Funding}

This study was part of a larger project funded by the Porticus foundation [\#GR-071645]. Open access publication enabled by the Bielefeld University.

\section{Usama EL-Awad}

Faculty of Psychology and Sports Sciences

Bielefeld University

Universitätsstraße 25

33615 Bielefeld

Germany

usama.el-awad@uni-bielefeld.de 